\title{
PREFERENCIAS Y PERCEPCIONES SOCIALES SOBRE LA MULTIFUNCIONALIDAD DEL MEDIO RURAL EN CASTILLA Y LEÓN
}

\author{
Margarita Rico González \\ ETS de Ingenierías Agrarias. Universidad de Valladolid \\ mrico@iaf.uva.es \\ José A. Gómez-Limón Rodríguez \\ Facultad de Derecho y Ciencias Económicas y Empresariales. Universidad de Córdoba \\ jglimon@uco.es
}

\section{RESUMEN}

El objetivo de este trabajo es analizar la demanda social relacionada con la multifuncionalidad rural. Con este propósito se ha realizado un estudio de opinión pública sobre las preferencias de la población de Castilla y León acerca de las diversas funciones que deberían cumplir los espacios rurales. La metodología empleada para cuantificar la importancia relativa de las diferentes funciones propuestas ha sido el Proceso Analítico Jerárquico. Los resultados obtenidos confirman las preferencias sociales realmente a favor de un mundo rural multifuncional.

Palabras clave: Espacio rural, diversificación funcional, demanda social, desarrollo rural, Proceso Analítico Jerárquico, Castilla y León.

\section{ABSTRACT}

The objective of this paper is to analyze social demand regarding rural multifunctionality. For this purpose, a public opinion survey has been implemented concerning the social preferences in Castilla y León (Spain) about the several functions that rural spaces should develop. The methodology chosen to assess the relative importance of the different functions

Fecha de recepción: marzo 2011.

Fecha de aceptación: julio 2012. 
proposed has been the Analytical Hierarchy Process. Results show that regional society prefers real multifunctional rural territories.

Key words: Rural areas, functional diversification, social demand, rural development, Analytical Hierarchy Process, Castilla y León (Spain).

\section{INTRODUCCIÓN Y OBJETIVOS}

Los procesos cíclicos de crecimiento y crisis económicas que han sufrido los países europeos en los últimos 50 años han acentuado considerablemente los desequilibrios territoriales entre zonas urbanas y zonas rurales, si bien es cierto que no todas las zonas rurales se han comportado del mismo modo (Brouwer, 2004; OECD, 2006). En España, algunos territorios han sabido hacer frente a la crisis provocada por la modernización de la agricultura a través de la especialización de sus producciones agrarias, o bien diversificando su economía, mientras que los espacios rurales situados en el litoral y en los anillos de las ciudades se han caracterizado por su dinamismo económico.

Sin embargo, una gran parte del territorio rural español se ha resentido gravemente desde un punto de vista demográfico, económico y social. Se trata de zonas geográficamente situadas en el interior peninsular, pertenecientes principalmente a Castilla y León y a Aragón, así como espacios de montaña de otras comunidades autónomas, donde la pérdida de importancia relativa de la agricultura en términos de renta y empleo y la dificultad de desarrollo de otras actividades productivas y de los servicios a la población, han motivado el éxodo de sus habitantes (González Regidor y Troitiño, 2008) y un proceso circular de envejecimiento, masculinización y falta de relevo generacional (Baraja, 2003; Molinero et al., 2004). Ante un panorama como el descrito, desde los años ochenta las administraciones públicas comenzaron a tomar en cuenta la problemática del mundo rural y la necesidad de intervención para tratar de paliar en la medida de lo posible los desequilibrios territoriales que se estaban acentuando cada vez con mayor intensidad. Todas estas políticas ponen de relieve la necesidad de que los territorios rurales sean multifuncionales y sepan adaptarse a la nueva situación que impera en los mercados y a los requerimientos de la sociedad, apostando por la diversificación como estrategia para mejorar sus maltrechas economías.

El concepto de multifuncionalidad surge en primer lugar referido al sector agrario (OECD, 2001 y 2003; Gómez-Limón y Barreiro, 2007) y a su capacidad de ofrecer otros bienes y servicios más allá de la tradicional producción de alimentos y materias primas, como son los relacionados con el medio ambiente (soporte de hábitats, paisaje...) y con su funcionalidad social (viabilidad de la vida rural, patrimonio cultural...), exista o no mercado para cada uno de ellos ${ }^{1}$. Esa concepción multifuncional de la agricultura (multifuncionalidad

1 La actividad agraria genera a través de procesos de producción conjunta bienes y servicios susceptibles de ser intercambiados en los mercados (bienes privados), y otros que carecen de mercado y que tienen carácter de bienes públicos, como son buena parte de las externalidades ambientales y sociales. Este concepto de multifuncionalidad se sustenta igualmente en el concepto de fallo de mercado, en la medida que la ausencia de remuneración de los productores por la generación de bienes y servicios de carácter público, puede provocar una producción inferior a la que sería deseable socialmente, generándose de esta manera una ineficiencia en la asignación (OECD, 2003). 
en su visión sectorial) se ha trasladado posteriormente al conjunto del medio rural, tomando así en consideración a todas aquellas actividades propias del ámbito rural que, sin ser de naturaleza meramente agraria, se desarrollan igualmente en estos territorios, como son las actividades industriales, ambientales, residenciales, recreativas o culturales (Van Huylenbroeck y Durand, 2003; Maya e Hidalgo, 2009). De este modo, y tal y como afirman Moyano y Garrido (2007), la multifuncionalidad rural se basa en el territorio (multifuncionalidad en su visión territorial) y se refiere a la multiplicidad de funciones que desempeñan las áreas rurales desde una concepción integral de sus potencialidades, independientemente de que en ellas haya o no actividad agraria. Atendiendo a esta definición, el estudio de la multifuncionalidad rural, tanto desde el punto de vista de la oferta (capacidad de producir bienes y servicios privados y públicos en el medio rural) como de la demanda (bienestar social asociado a distintas 'cestas' de bienes y servicios generados en el campo), en su más extenso sentido, constituye una herramienta útil para determinar el óptimo social en relación a la funcionalidad del medio rural. La finalidad de todo este tipo de estudios sería ayudar a la 'gobernanza' del medio rural, al objeto de maximizar el grado de satisfacción del conjunto de la sociedad por la provisión de bienes y servicios multifuncionales (Gómez-Limón y Barreiro, 2007; Kallas et al., 2007). Para ello, se considera fundamental la participación del conjunto de la población en todas las fases de una estrategia de desarrollo rural: descripción de problemas y necesidades, establecimiento de objetivos, elaboración de la estrategia, participación en las medidas propuestas y evaluación de resultados (Hoggart et al., 1995; Quintana et al., 1999; OECD, 2006). En dicho marco de actuación, el análisis de la demanda de la multifuncionalidad de un determinado territorio constituye el paso previo para la formulación de políticas públicas legítimas que den respuestas a los problemas rurales y atiendan a las demandas sociales (Van Huylenbroeck y Durand, 2003; Maya, 2008).

Al hilo de lo expuesto, el objetivo principal del trabajo se centra en estudiar la demanda social de la multifuncionalidad rural a través del análisis de las preferencias y percepciones del conjunto de la ciudadanía en cuanto a las funciones que pueden desempeñar las zonas rurales. Para ello se recopila y examina información sobre: a) las preferencias de la población acerca de las diversas funciones que han de cumplir los espacios rurales, b) sus percepciones en cuanto al desempeño actual de cada función, y c) las opiniones referidas a la evolución de dicho desempeño multifuncional en la última década. Asimismo, se persigue estudiar la heterogeneidad de la población en función de tales preferencias y percepciones. Para llevar a cabo esta investigación, se ha seleccionado el medio rural de la comunidad autónoma de Castilla y León como unidad susceptible de análisis empírico. Esta elección se justifica por tratarse de una de las regiones españolas más fuertemente castigadas por la decadencia económica rural, en la que las actuaciones de desarrollo rural son realmente prioritarias al objeto de lograr la necesaria vertebración territorial.

Planteada así la investigación, el interés de la misma puede considerase doble. En primer lugar como caso de estudio innovador en esta línea, reportando resultados útiles para el diseño e implementación de políticas públicas de desarrollo rural en Castilla y León. En segundo lugar, teniendo en cuenta que dichos resultados difícilmente pueden ser extrapolables a otros territorios, al ser estos específicos de la sociedad analizada, este trabajo puede resultar igualmente interesante tanto por la metodología propuesta, perfectamente aplicable a cualquier otro espacio, como por su propia finalidad, que no es otra que evidenciar la nece- 
sidad de plantear los objetivos de la política de desarrollo rural de acuerdo con las demandas sociales, persiguiendo así que ésta sea una auténtica política al servicio de la ciudadanía.

Para la consecución de los objetivos propuestos, el trabajo se ha estructurado del siguiente modo. Después de esta introducción, en el segundo apartado se desarrolla la metodología empleada en el análisis empírico. En el tercer apartado se efectúa una breve descripción de las principales funciones que actualmente desempeña el ámbito objeto de estudio, el medio rural de Castilla y León. El apartado cuarto está dedicado a ofrecer los resultados obtenidos acerca de la opinión pública (preferencias y percepciones) sobre la multifuncionalidad rural. El quinto y último apartado se destina a plantear las conclusiones centrales extraídas.

\section{METODOLOGÍA}

\section{Antecedentes de la investigación}

El estudio empírico de la multifuncionalidad del medio rural tradicionalmente se ha centrado en el análisis del conjunto de bienes y servicios que éste puede generar al conjunto de la sociedad (análisis desde la óptica de la oferta). En este sentido cabe destacar, entre otros, los trabajos de Clout (1991), Marsden et al. (1993), García Sanz e Izcara (2000) o Brouwer (2004). Sin embargo, mucho más escasos son los trabajos referidos al análisis de la demanda social de la multifuncionalidad rural. En esta última línea cabe reseñar los trabajos de Gómez-Limón et al. (2007), que estudia las percepciones de los castellanos y leoneses acerca de la despoblación rural en esa región, y el de Rico y Gómez-Limón (2008), que analiza la opinión pública acerca de los objetivos de las políticas públicas de desarrollo rural en Castilla y León. Finalmente, cabe señalar como antecedente de este trabajo el Agrobarómetro de Andalucía (IESA, 2008), a través del cual se recoge periódicamente información sobre la opinión de los andaluces en relación a la agricultura y el mundo rural. A pesar de estos antecedentes, no se tiene constancia de ningún trabajo que haya analizado de forma sistematizada las percepciones del conjunto de la sociedad acerca de las múltiples funcionalidades de una determinada zona rural, tal y como aquí se propone. Esta circunstancia pone de relieve el carácter innovador de la investigación.

\section{Identificación de las funciones del medio rural}

La primera etapa de la aplicación empírica realizada ha consistido en identificar a priori las principales funciones que cabe atribuir a los espacios rurales, para lo cual se ha realizado una amplia revisión bibliográfica. En consecuencia, los bienes y servicios que los individuos pueden demandar del medio rural se pueden agrupar en cuatro funciones genéricas diferenciadas (Clout, 1991; Hoggart et al., 1995; Gómez Mendoza, 2001; Van Huylenbroeck y Durand, 2003; Pérez y Caballero, 2004; Marsden, 2006): función económica, función medioambiental, función residencial y función cultural y recreativa. Posteriormente, y partiendo de la literatura antes mencionada, así como de la información recogida en el Plan de Desarrollo Rural de Castilla y León (CAG, 2009), se ha establecido un catálogo inicial de funciones específicas que cabría considerar dentro de cada una de las funciones genéricas anteriormente enumeradas para el caso de Castilla y León. La estructura jerárquica resultante 
(funciones genéricas y específicas) ha sido discutida con un grupo de ocho expertos en temas de desarrollo rural de la región (tres técnicos procedentes de las administraciones públicas, tres profesores de universidad y dos responsables de grupos de acción local) en una sesión de trabajo conjunta. Fruto de este debate se ha podido consensuar, en primer lugar, la idoneidad de dicha estructura jerárquica para la realización de este trabajo. En segundo lugar, este debate ha permitido seleccionar las funciones específicas más relevantes para el caso de estudio, que serán las que se consideren en la aplicación empírica a realizar. Tales funciones específicas son las que señalan en la Tabla 1.

Tabla 1

LAS PRINCIPALES FUNCIONES DEL MEDIO RURAL

\begin{tabular}{|l|l|}
\hline \multicolumn{1}{|c|}{$\begin{array}{c}\text { FUNCIONES } \\
\text { GENÉRICAS }\end{array}$} & \multicolumn{1}{c|}{ FUNCIONES ESPECÍFICAS } \\
\hline $\begin{array}{l}\text { Funciones } \\
\text { económicas }\end{array}$ & $\begin{array}{l}\text { Base territorial para el desarrollo de actividades agrícolas, gana- } \\
\text { deras y forestales } \\
\text { Base territorial para el desarrollo de la industria agroalimentaria } \\
\text { Base territorial para el desarrollo de otro tipo de industrias } \\
\text { Base territorial para el desarrollo de empresas de servicios }\end{array}$ \\
\hline $\begin{array}{l}\text { Funciones } \\
\text { medioambientales }\end{array}$ & $\begin{array}{l}\text { Base territorial para el disfrute del paisaje, flora y fauna } \\
\text { Base territorial de una red de espacios naturales protegidos (par- } \\
\text { ques naturales) } \\
\text { Contribución a la calidad de las aguas y del aire del conjunto de } \\
\text { la región }\end{array}$ \\
\hline $\begin{array}{l}\text { Funciones } \\
\text { residenciales }\end{array}$ & $\begin{array}{l}\text { Asentamiento de las sociedades rurales (pueblos) } \\
\text { Zona residencial de primera y segunda vivienda para individuos } \\
\text { urbanos }\end{array}$ \\
\hline $\begin{array}{l}\text { Funciones culturales } \\
\text { y recreativas }\end{array}$ & $\begin{array}{l}\text { Mantenimiento del legado patrimonial histórico-artístico y el fol- } \\
\text { clore } \\
\text { Marco para actividades de ocio (turismo rural, deportes al aire li- } \\
\text { bre...) }\end{array}$ \\
\hline
\end{tabular}

Fuente: elaboración propia.

\section{La importancia relativa de las diversas funciones: El Proceso Analítico Jerárquico (AHP)}

Como se ha comentado anteriormente, el primero de los objetivos específicos del trabajo es analizar las preferencias de la población castellana y leonesa acerca de las diversas funciones que ha de cumplir el espacio rural regional. El análisis así planteado debe determinar la importancia relativa de las diferentes funciones o atributos que tiene un concepto complejo como es el de la multifuncionalidad del medio rural. Para lograr tal fin, se ha empleado el Proceso Analítico Jerárquico (AHP), un método que ha sido utilizado de manera satisfactoria en trabajos que han determinado la demanda monetaria de los diferentes atributos comprendidos dentro de la multifuncionalidad agraria (Variyam et al. (1990); Gourlay y Slee 
(1998); Duke y Hull-Hyde (2002) o Kallas et al. (2007)). La metodología AHP fue creada por Saaty (1980) como técnica estructurada pero flexible para la toma de decisiones en un contexto multicriterio. Ésta se basa en la formalización de problemas de decisión complejos empleando una estructura jerárquica, tal y como se expone para nuestro caso en la Figura 1. Así, el concepto de multifuncionalidad del medio rural se descompone en primer lugar en sus cuatro funciones genéricas (económica, medioambiental, residencial y cultural y recreativa), que a su vez dan lugar a las 11 funciones específicas recogidas en la Tabla 1.

Dentro de esta estructura jerárquica, la importancia relativa o ponderaciones de las funciones genéricas y las funciones específicas $\left(w_{i}\right)$ se obtienen mediante una serie de comparaciones por pares, que determinan la intensidad de preferencia entre cada par de opciones consideradas. Para ello, como propone Saaty (1980), se ha utilizado una escala lineal que va de 1 (igual importancia entre funciones) a 9 (importancia absoluta de una función sobre la otra). De esta forma, para determinar la importancia relativa de cada una de las funciones propuestas, los encuestados (individuos muestreados como representantes del conjunto de la sociedad) deben realizar dos tipos de comparaciones: (a) comparaciones por pares de las cuatro funciones genéricas, y (b) comparaciones por pares entre las funciones específicas consideradas en cada caso. Así, para cada decisor (para cada encuestado $k$ en nuestro caso), se han generado cinco matrices, una para las funciones genéricas y las cuatro restantes para las funciones específicas pertenecientes a cada función genérica, siguiendo la siguiente estructura (matrices de Saaty):

$$
A_{k}=\left[\begin{array}{cccc}
a_{11 k} & a_{12 k} & \ldots & a_{1 n k} \\
a_{21 k} & a_{22 k} & \ldots & a_{2 n k} \\
\ldots & \ldots & a_{i j} & \ldots \\
a_{n 1 k} & a_{n 2 k} & \ldots & a_{n n k}
\end{array}\right]
$$

donde $a_{i j k}$ representa el valor de comparación entre la función $i$ y la función $j$ para el individuo $k$ y $n$ es el número total de funciones a considerar en cada caso (que no es el mismo en todas las matrices). Para el caso de un decisor (encuestado en nuestro caso) perfectamente racional o 'consistente' ${ }^{2}$, se verifica que los valores otorgados a las comparaciones por pares representan en realidad ratios entre las ponderaciones concedidas a las correspondientes funciones: $a_{i j k}=w_{i k} / w_{j k}$ para todo $i$ y $j$. Así, las $n$ ponderaciones o pesos individuales de cada función $\left(w_{i k}\right)$ podrían fácilmente determinarse a partir de los $n(n-1) / 2$ valores de $a_{i j k}$ que este individuo ha declarado.

Sin embargo, la perfecta consistencia de los decisores raramente se da en la realidad. Por ello, para las matrices de Saaty que presenten cierto grado de inconsistencia, se han propuesto diferentes técnicas destinadas a estimar el vector de prioridades $\left(\vec{w}_{k}=\left(w_{1 k}, \ldots w_{k}, \ldots w_{k}\right)\right)$ que mejor se adapte al vector real de ponderaciones del individuo $k$. En este sentido, en este trabajo se ha optado por el método de operativa más simple para la estimación de tales prioridades, como es el de la media geométrica (Aguarón y Moreno-Jiménez, 2000). Así,

2 Se considera que un decisor (encuestado en nuestro caso) es perfectamente racional o 'consistente' cuando se cumple que $a_{i l} \cdot a_{l j}=a_{i j}$ para toda función $i, j$ y $l$. 
el cálculo de los pesos particulares que cada encuestado asigna a los diferentes atributos se realiza aplicando la siguiente expresión algebraica:

$$
w_{i k}=\sqrt[n]{\prod_{j=1}^{j=n} a_{i j k}} \quad \forall i, j \in n
$$

En principio esta técnica del AHP se pensó para decisores individuales, pero pronto se extendió como técnica válida para la decisión de grupos (Easley et al., 2000). En este sentido, Forman y Peniwati (1998) proponen la media geométrica para agregar las ponderaciones obtenidas para cada individuo $k\left(w_{i k}\right)$ al objeto de estimar las ponderaciones representativas del conjunto del grupo en el ámbito social:

$$
W_{i}=\sqrt[m]{\prod_{k=1}^{k=m} W_{i k}}
$$

donde $w_{i}$ es el peso agregado de la función $i$.

\section{La encuesta}

Para recoger información acerca de la opinión pública de la sociedad de la comunidad autónoma de Castilla y León, se ha realizado una encuesta ad hoc. Así, se ha elaborado un

Tabla 2

FICHA TÉCNICA DE LA ENCUESTA

\begin{tabular}{|l|l|}
\hline Población objeto de estudio & $\begin{array}{l}\text { Personas residentes en Castilla y León con edades iguales } \\
\text { o superiores a } 16 \text { años }(2.137 .268 \text { personas según el Pa- } \\
\text { drón de habitantes de 2008). }\end{array}$ \\
\hline Tamaño de la muestra & 725 entrevistas. \\
\hline Tipo de entrevista & $\begin{array}{l}\text { Presencial mediante cuestionario, realizada en los domi- } \\
\text { cilios. }\end{array}$ \\
\hline Eipo de muestreo & $\begin{array}{l}\text { Polietápico, estratificado por conglomerados (afijación } \\
\text { proporcional al tamaño del hábitat), con selección de las } \\
\text { unidades primarias de muestreo (municipios) mediante un } \\
\text { procedimiento aleatorio proporcional, y selección de las } \\
\text { unidades últimas de muestreo (individuos) mediante rutas } \\
\text { aleatorias y cuotas de sexo y edad. }\end{array}$ \\
\hline Elror & $\begin{array}{l}\text { El nivel de error absoluto máximo esperado de los resul- } \\
\text { tados de la encuesta, para las frecuencias de cada variable, } \\
\text { es de } \pm 3,71 \%, \text { para un nivel de confianza del 95,5\%, } 2 \\
\text { sigmas p=q=0,5. }\end{array}$ \\
\hline Fechas de trabajo de campo & Del 14 de septiembre al 2 de octubre de 2009. \\
\hline
\end{tabular}

Fuente: Elaboración propia. 
cuestionario específico compuesto por un total de 39 preguntas cerradas acerca de las preferencias y percepciones personales en cuanto a las funciones desempeñadas por el medio rural castellano y leonés. Dichas preguntas han sido divididas en tres bloques diferenciados, teniendo en cuenta los distintos objetivos específicos de la investigación: a) Preferencias en relación a las funciones a desarrollar por el medio rural (17 preguntas); b) Percepción del desempeño actual de las funciones realizadas por el medio rural (11 preguntas); c) Percepción de la evolución reciente del desempeño de las funciones realizadas por el medio rural (11 preguntas). Adicionalmente se han añadido otras cinco cuestiones para la caracterización sociodemográfica de los encuestados, que han sido empleadas para el análisis de la heterogeneidad de la opinión pública. Al objeto de lograr resultados representativos del conjunto de la sociedad castellana y leonesa, se extrajo una muestra de 725 individuos entre la población regional mayor de 16 años. La ficha técnica de la encuesta se muestra en la Tabla 2.

\section{EL CASO DE ESTUDIO: EL MEDIO RURAL DE CASTILLA Y LEÓN}

La Comunidad Autónoma de Castilla y León es la región española más extensa (94.200 $\mathrm{km}^{2}$ ), y está situada en el interior de la Península Ibérica. Uno de los factores característicos de este territorio es su marcado carácter rural y su acentuada tradición agraria, uno de los motivos principales por el que sus municipios rurales se han visto especialmente perjudicados por la crisis del sector primario acaecida a partir de la segunda mitad del siglo XX. Este hecho, unido al reducido tamaño de muchos de sus núcleos de población (López Trigal, 2003) y a la consiguiente dificultad para mantener actividades productivas en un entorno cada vez más competitivo (Molina, 2003), ha motivado la decadencia económica y sociodemográfica de muchos de estos espacios. Así, la estructura demográfica de Castilla y León se caracteriza por un acusado desequilibrio poblacional, de modo que coexisten un gran número de pequeños municipios de menos de 2.000 habitantes, que territorialmente hablando ocupan el $86,1 \%$ del espacio regional pero donde tan solo reside el 26,2\% de la población y un grupo muy reducido de municipios medianos y grandes (134 localidades de más de 2.000 habitantes) donde habita el 73,8\% de la población de esta región (Mapa 1).

En lo que respecta a las funciones económicas desarrolladas en el medio rural castellano y leonés, es preciso señalar la importante orientación agraria que aún mantiene este territorio (Miranda y Rico, 2007), de tal modo que en 2010 el sector primario representaba el 6,0\% del PIB regional, empleando al 6,6\% del total de la población ocupada $(2,4 \%$ y $4,2 \%$ respectivamente para el conjunto de España). Por su parte, el sector forestal tan sólo contribuye con un $0,2 \%$ al PIB regional, una proporción muy escasa teniendo en cuenta la gran potencialidad de este sector, tanto en lo que se refiere a sus aspectos tangibles como intangibles. La alta dependencia del sector agrario en las zonas rurales de Castilla y León es uno de los motivos que justifican la escasa diversificación económica existente. No obstante, cabe comentar la significación de la industria agroalimentaria, asociada a las producciones agrícolas y ganaderas locales (García Sanz, 2003). El desarrollo de otros sectores industriales alternativos a la agroindustria es bastante puntual, aunque pueden citarse el sector metalúrgico y el de transformación de la madera. De igual forma, el sector servicios tampoco presenta dinamismo en las zonas rurales, dada la progresiva despoblación de los núcleos más pequeños que está acentuando el desmantelamiento de los servicios sociales básicos. Asimismo, las actividades 


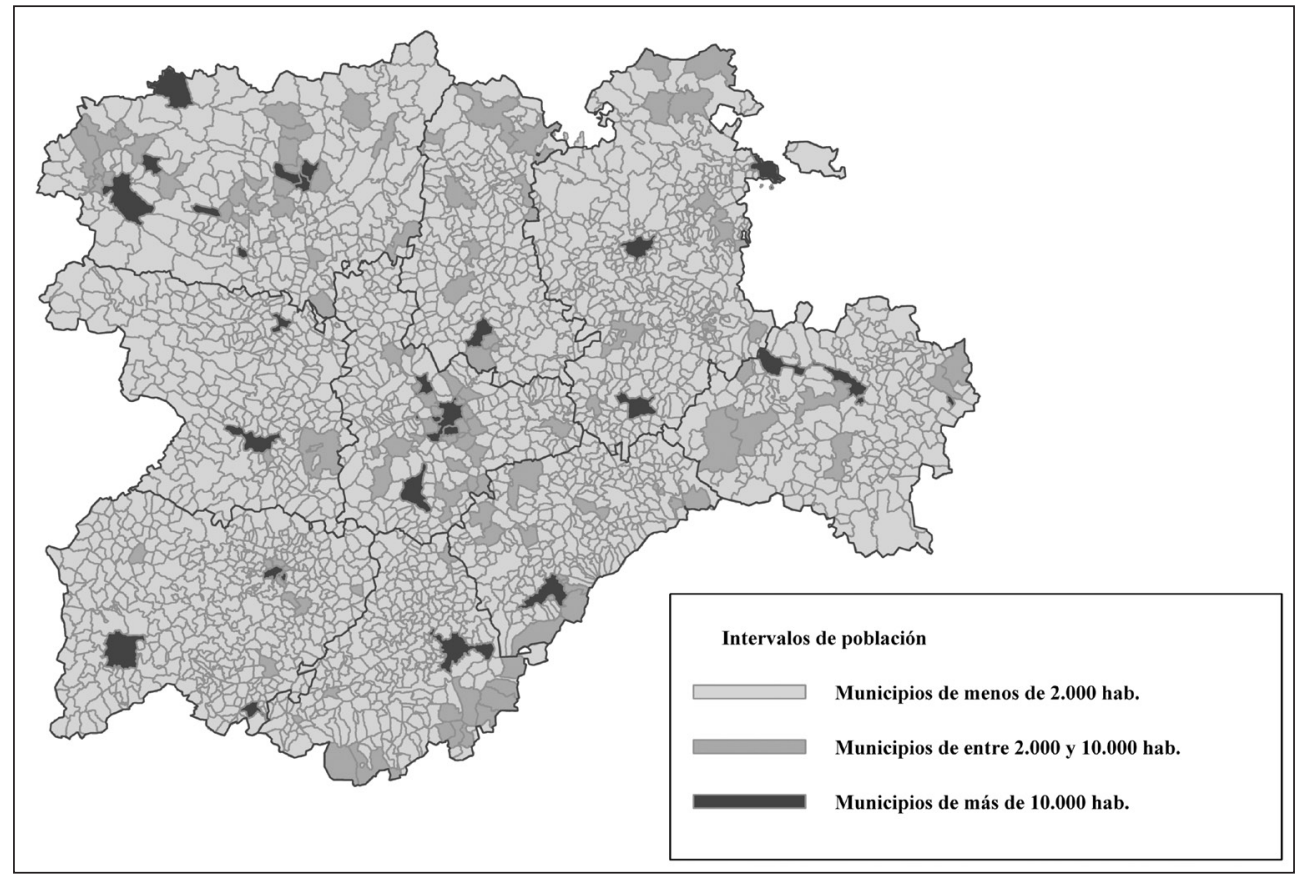

Fuente: Elaboración propia a partir de los datos del Padrón de Habitantes del Instituto Nacional de Estadística.

comerciales, financieras y demás tipos de servicios tampoco son rentables en las pequeñas localidades, con lo que cada vez más éstos tienden a concentrarse en localidades mayores. Los únicos servicios que en los últimos años han evolucionado positivamente son las actividades turísticas y hosteleras, en consonancia con la función lúdica de estos espacios.

En lo relativo a las funciones medioambientales, cabe destacar que el ámbito rural de Castilla y León proporciona una amplia diversidad de ecosistemas, paisajes y entornos singulares, que constituyen el hábitat para una gran cantidad de especies vegetales y faunísticas, constituyéndose en un territorio con una gran riqueza natural, lo que redunda en la calidad medioambiental del conjunto de la Comunidad Autónoma. Prueba de ello es la gran extensión de la Red Natura 2000 en la región, que cuenta con 2,5 millones de hectáreas (el 26,1\% del total del territorio de la Comunidad).

Para analizar la funcionalidad residencial del medio rural de Castilla y León es necesario aludir a la existencia de un profundo desequilibrio territorial (García Pascual, 2003). Si bien existen algunos municipios que mantienen un alto grado de dinamismo (los periurbanos y los que han sabido aprovechar económicamente algún tipo de ventaja competitiva), la mayor parte del territorio rural se encuentra en una situación crítica, con una gran cantidad de municipios pequeños que padecen una continua despoblación, elevado grado de envejecimiento 
de sus habitantes y acentuado desequilibrio poblacional según sexos (Rico y Gómez, 2009). Entre dichos municipios, los que están padeciendo los mayores problemas son los que tienen menos de 2.000 habitantes (2.114 localidades en total), que representan el 86,3\% del territorio, pero donde solamente habita el $26,2 \%$ de la población regional. De esta forma se configura un medio rural prácticamente «vacío» (Gómez-Limón et al., 2007), con una densidad de población de 8,4 hab./ $\mathrm{km}^{2}$ (frente a los 27,2 y 92,4 hab./ $\mathrm{km}^{2}$ del conjunto de Castilla y León y España, respectivamente). Sin embargo, en los últimos años el campo parece estar siendo el destino residencial de determinados grupos de población (retornados, neorrurales, segunda residencia...) que buscan en el medio rural alternativas a la forma de vida urbana o incluso una salida laboral (Molinero y Baraja, 2011).

Finalmente, y aludiendo a la funcionalidad cultural y recreativa del medio rural de Castilla y León, puede destacarse la gran riqueza patrimonial, cultural y tradicional que poseen estos territorios, con numerosos bienes de interés histórico-cultural. Dentro de estas funciones recreativas hay que aludir necesariamente a la relevancia que en los últimos años representan las actividades de turismo rural, que han cambiado la fisonomía de muchos municipios y han impulsado la diversificación de su tejido socioeconómico, siendo la región española que posee mayor número de alojamientos de turismo rural y recibe mayor número de visitantes anuales de esta modalidad turística.

De lo expuesto en este apartado se puede afirmar que las zonas rurales de Castilla y León ostentan una amplia potencialidad para el desarrollo efectivo de cada una de las funciones consideradas (Maya, 2006). Sin embargo, también puede deducirse que en muchas ocasiones, y debido a diversos factores, especialmente por el proceso de descapitalización demográfica, esa potencialidad no está siendo aprovechada.

\section{RESULTADOS DEL ESTUDIO DE OPINIÓN PÚBLICA ACERCA DE LA MULTIFUNCIONALI- DAD RURAL}

\section{Preferencias sociales y aproximación a la función de utilidad social}

La aplicación del método del AHP a cada individuo de la muestra y la posterior agregación de las ponderaciones resultantes ha permitido obtener, como primer resultado del trabajo, una cuantificación de la importancia relativa de cada una de las funciones genéricas y específicas que debe desempeñar el medio rural según la opinión del conjunto de la sociedad castellana y leonesa. Estos resultados pueden visualizarse en la Figura 1. El primer hecho a destacar en relación a las ponderaciones agregadas de las funciones genéricas analizadas, es que todas ellas son consideradas relevantes por la sociedad regional. De hecho, hasta la función menos valorada, la funcionalidad cultural y recreativa, obtiene una prioridad elevada, que alcanza el 19,5\%. Estos resultados ponen de manifiesto la existencia de una demanda social a favor de un espacio rural realmente multifuncional, como territorio que debe desempeñar adecuadamente todas estas funciones al mismo tiempo. Efectivamente, la sociedad castellana y leonesa desea que en el medio rural se desarrollen tanto las funciones tradicionales, de carácter meramente productivo y residencial, como otras de carácter más contemporáneo, basadas en la sostenibilidad ambiental y en el aprovechamiento de sus recursos patrimoniales y recreativos. 
A pesar de que todas las funciones genéricas cabe calificarlas como relevantes para la sociedad regional, existen diferencias significativas en los pesos otorgados a cada una de ellas. Así, la funcionalidad económica aparece con una ponderación significativamente más elevada que el resto, con un $36,2 \%$. Este hecho revela la voluntad de la sociedad regional de desarrollar económicamente las zonas rurales de la región, considerando estos territorios como espacios donde llevar a cabo de forma prioritaria todo tipo de actividades productivas, especialmente las relacionadas con los servicios, la agricultura y la industria agroalimentaria. Se evidencia así una preferencia de la ciudadanía por un desarrollo económico basado en la diversidad productiva, dejando atrás la sinonimia rural-agraria que ha caracterizado el medio rural en el pasado. En cualquier caso, es necesario tener en cuenta el contexto de crisis económica generalizada en que se ha desarrollado la encuesta, circunstancia que ha podido influir en los resultados con una sobreponderación de tales funciones. Esta última idea se trata tan sólo de una hipótesis que debería ser contrastada en un futuro, analizando de nuevo las preferencias sociales una vez la situación económica se haya normalizado. Tras las funciones económicas, en un segundo escalón de las preferencias sociales se posicionan las funciones medioambiental y residencial $(22,4 \%$ y $21,8 \%$, respectivamente), sin que existan diferencias significativas entre sus pesos agregados. En último lugar aparece la funcionalidad cultural y recreativa, que presenta la ponderación significativamente más baja (19,5\%).

En relación a las funciones específicas cabe reseñar que la función residencial de asentamiento de las comunidades rurales, (peso agregado medio del 14,1\%), es la que presenta la importancia significativamente mayor. Este hecho puede relacionarse con los estrechos vínculos familiares que aún mantienen los individuos urbanos con los habitantes de las zonas rurales (la mayoría son urbanitas de primera y segunda generación), de modo que para muchos el pueblo sigue representando una referencia familiar, dado su originen rural, además de su destino vacacional o de descanso semanal. Por ello, la pervivencia del agro y su sociedad constituyen una prioridad para gran parte de la población, tanto urbana como rural. Le siguen a distancia, sin encontrarse diferencias significativas entre ellas, la función económica de base territorial para empresas de servicios $(11,0 \%)$, la función ambiental de contribuir a la mejora del medioambiente regional $(10,2 \%)$, la económica de base para empresas agrarias $(10,0 \%)$ y las funciones recreativas y culturales, como marco para actividades de ocio $(9,8 \%)$ y para el mantenimiento del legado patrimonial $(9,7 \%)$. En el otro extremo destaca la función ambiental como base territorial para proporcionar una red de espacios naturales protegidos, que con tan sólo el 4,6\% de la importancia total se constituye como la función significativamente menos relevante. Este último resultado parece apuntar a que la demanda social de espacios protegidos en esta región tiene una finalidad básicamente utilitarista, siendo éstos más valorados por su capacidad de acoger actividades recreativas (valor de uso) que por su función conservadora de ecosistemas singulares (valores de no-uso: de 'existencia' o de 'legado').

Finalmente, en cuanto al estudio de las preferencias sociales respecto a la multifuncionalidad rural, ha parecido igualmente oportuno realizar un análisis de la heterogeneidad de la población. Para ello se ha aplicado la técnica de la regresión lineal múltiple. Así, se han construido 11 modelos de regresión en los cuales las variables dependientes han sido los distintos pesos asignados a cada una de las funciones específicas del medio rural $\left(w_{i}\right)$. En 


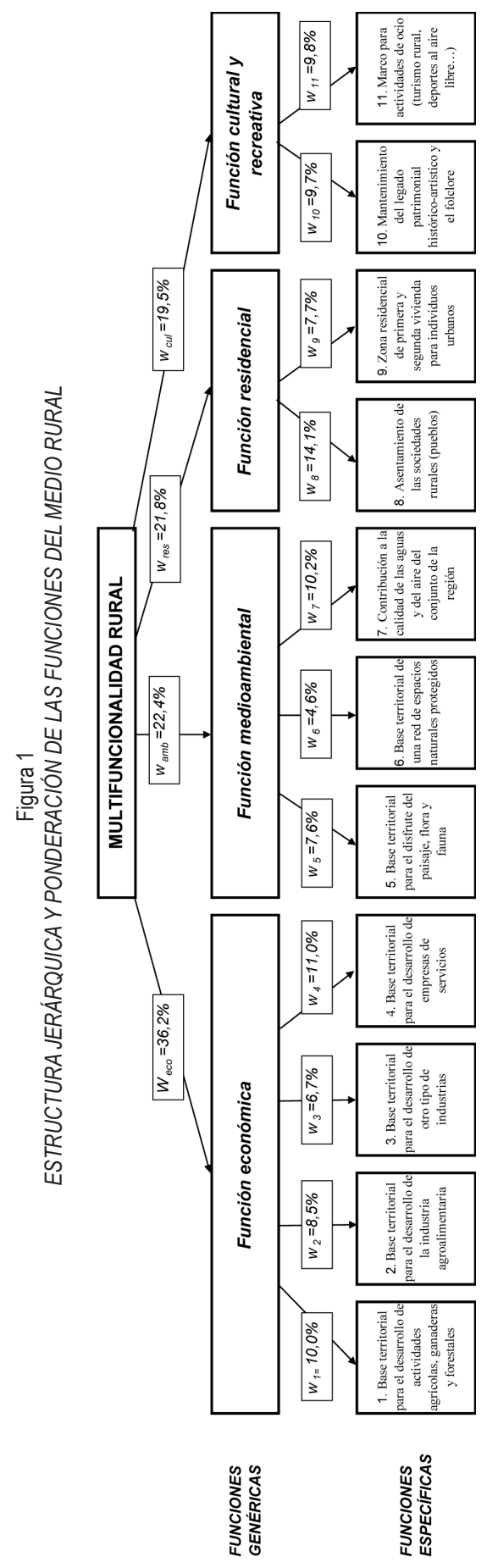


todas estas regresiones se han considerado como variables explicativas las características socioeconómicas y demográficas recogidas en la encuesta. Además, en cada una de estas regresiones se ha aplicado un procedimiento 'paso a paso hacia atrás' al objeto de obtener modelos donde únicamente aparezcan las variables independientes realmente significativas. Los criterios de entrada y salida considerados para estas regresiones han sido $p$-valores de 0,05 y 0,10 , respectivamente. Los resultados de los modelos finales son los que se muestran en la Tabla 3. De los resultados así obtenidos, lo primero que conviene comentar es que si bien todos los modelos son significativos ( $p$-valores del estadístico F menores a 0,001 ), su poder explicativo es bajo, sin llegar en ningún caso a explicar más del 10\% de varianza de las diferentes ponderaciones. En cualquier caso, los coeficientes que han resultado significativos en los diferentes modelos de regresión son de interés en la medida que permiten conocer cuáles de los factores sociodemográficos recogidos en la encuesta condicionan las preferencias sociales sobre este tema, tal y como se resumen a continuación.

En cuanto a las funciones económicas, destaca cómo la importancia dada a las actividades agrarias y agroalimentarias se incrementa a medida que aumenta la edad (agricultura y agroindustria como actividades económicas tradicionalmente preponderantes en el medio rural), y tiene una mayor relevancia entre los residentes en núcleos rurales (municipios más dependientes de ambas actividades, tanto por la residencia de los propios agricultores como por la localización de empresas agroindustriales y de servicios relacionadas con la agricultura). Por su parte, la funcionalidad económica basada en las empresas de servicios es sobre todo valorada por los ciudadanos de mayor edad (demanda de empresas que incrementen la calidad de vida en el medio rural), que viven en las ciudades, con mayor nivel educativo y de rentas más altas (demanda de empresas que posibiliten la realización de turismo rural o de otro tipo de actividades de ocio).

En relación a las funciones ambientales cabe comentar cómo las variables que han resultado ser más significativas han sido la edad y el hábitat. Así, las personas de mayor edad y residentes en las ciudades son las que otorgan una mayor importancia a la provisión de bienes y servicios ambientales a través de una red de espacios naturales protegidos, relegando a un segundo plano esta misma provisión a partir de las actividades tradicionales como la agricultura y la función del medio rural para mejorar la calidad ambiental del conjunto de la región. Este resultado parece determinar un mayor deseo de los ciudadanos urbanos de que la sostenibilidad ambiental se fomenta a través de espacios protegidos, donde los diferentes usos productivos estén limitados legalmente. Todo lo contrario ocurre con los habitantes rurales, que en muchos casos se muestran contrarios a este tipo de actuaciones, en la medida que originan conflictos con sus intereses económicos.

La importancia de las funciones residenciales del medio rural, tanto para la población rural como urbana, disminuye conforme aumenta la edad de los individuos (colectivo con menores demandas de bienes y servicios relacionados con la vivienda). Además, como parece lógico, los habitantes de las ciudades otorgan una mayor importancia que los rurales a la funcionalidad residencial para los urbanitas, dada la problemática de acceso a la vivienda existente en estos grandes núcleos de población. Finalmente, se aprecia cómo la variable renta también resulta ser explicativa, de tal manera que las personas de rentas más elevadas consideran más importante la función residencial relacionada con la pervivencia de las sociedades rurales que la relacionada con la urbanización rural para los individuos urbanos. 


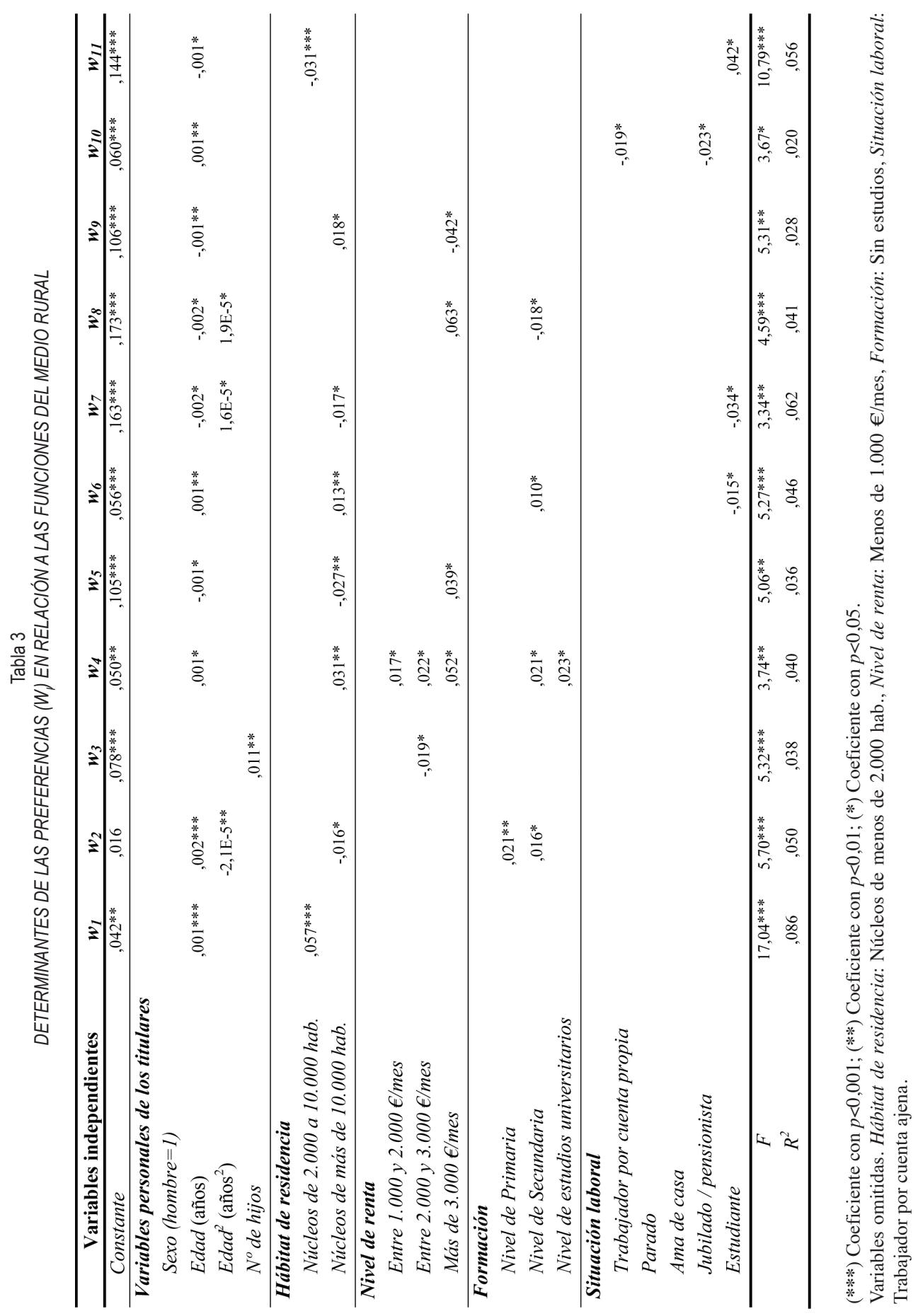


Cabría hipotetizar que este hecho está justificado por una preferencia de este colectivo social por el mantenimiento de la identidad cultural de las zonas rurales y por evitar una posible congestión de estas zonas por excesos urbanísticos planteados como oferta residencial de primera y segunda vivienda para los habitantes de las ciudades.

Finalmente, en lo que respecta a las funciones culturales y recreativas, cabe comentar que el mantenimiento del patrimonio cultural es considerado más importante por las personas de mayor edad (mayor valoración de un legado que consideran propio). Todo lo contrario ocurre para la función recreativa, donde son las personas más jóvenes, sobre todo si son estudiantes (mayor demanda de actividades de ocio al aire libre), las que opinan que este rol es más importante.

\section{Percepciones sociales sobre el desempeño actual de la multifuncionalidad rural}

La Tabla 4 muestra un descriptivo básico de los resultados obtenidos en relación a la opinión pública acerca del cumplimiento o desempeño actual de cada una de las funciones realizadas por el medio rural castellano y leonés (variables $C_{i}$ ), para lo cual se ha utilizado una escala de 0 (cumplimiento pésimo) a 10 (cumplimiento óptimo). En este sentido cabe destacar una relativa homogeneidad en las respuestas obtenidas para todas ellas, estando las medias comprendidas en un rango inferior a 1,5 puntos en una escala de 10, con un máximo de 5,34 y un mínimo de 4,07. En general, estas percepciones pueden considerarse como algo desalentadoras, muy en consonancia con la situación actual de deterioro de muchos espacios rurales. En cualquier caso, cabe comentar que las siguientes funciones presentan valoraciones promedio significativamente por encima de cinco: base territorial para el desarrollo de empresas de servicios $(5,36)$, mantenimiento del legado patrimonial $(5,34)$, marco para actividades de ocio $(5,26)$, residencia para las sociedades rurales $(5,22)$ y residencia para individuos urbanos $(5,21)$. Por el contrario, la sociedad regional considera en su conjunto que las siguientes funciones están desempeñadas ligeramente por debajo del nivel mínimo aceptado (valoración media significativamente por debajo de 5): base territorial para el desarrollo de otro tipo de industrias $(4,07)$, base territorial de una red de espacios naturales protegidos $(4,34)$, base territorial para el desarrollo de la industria agroalimentaria $(4,36)$, contribución a la calidad ambiental de la región $(4,62)$, base territorial para el desarrollo de actividades primarias tradicionales $(4,66)$ y provisión de servicios relacionados con el paisaje, flora y fauna (4,93). Así, en resumen, cabe interpretar que la sociedad regional, en general, se muestra ligeramente insatisfecha con el desempeño actual de las funciones económicas y medioambientales, pero tiene una percepción algo más positiva en cuanto al cumplimiento del conjunto de funciones residenciales y culturales y recreativas.

A tenor de estos resultados, si bien en general se constata una cierta insatisfacción pública en relación al cumplimiento de las funciones asignadas a las zonas rurales de Castilla y León, se puede destacar que las percepciones de la sociedad con respecto a alguna de las funciones analizadas no se ajusta plenamente a los datos objetivos disponibles en relación al medio rural de esta Comunidad Autónoma. Así, por ejemplo, puede ser objeto de debate el hecho de que la población en general tenga la opinión de que los espacios rurales castellanos y leoneses estén actualmente cumpliendo la función relacionada con el asentamiento de las sociedades rurales, con el hecho efectivo de que los pueblos estén cada vez más despoblados. 
Asimismo, parece paradójico que los ciudadanos consideren que no es suficiente la actual catalogación de espacios naturales protegidos existentes en la región, cuando su superficie se ha incrementado significativamente en los últimos años y actualmente cubren el $26 \%$ del territorio, tal y como se ha señalado anteriormente. El motivo que puede subyacer a este hecho tiene que ver con los posibles sesgos implícitos en las respuestas de las personas entrevistadas, ya que puede suceder que sus opiniones no aludan a la situación general del medio rural, que era lo que se les cuestionaba, sino a la situación específica de aquellos municipios en los que viven, conocen o visitan. En este sentido, esta circunstancia podría indicar una falta de información de muchos de los habitantes de la región en torno a la situación global de los territorios de la Comunidad Autónoma y a alguna de las actuaciones que se están implementando al abrigo de los programas de desarrollo rural.

Tabla 4

ESTADÍSTICOS DESCRIPTIVOS DE C, Y $E_{l}$

\begin{tabular}{|c|c|c|c|c|}
\hline \multirow[t]{2}{*}{ Funciones especificas } & \multicolumn{2}{|c|}{$\begin{array}{c}\text { Cumplimiento actual } \\
\left(C_{i}\right)\end{array}$} & \multicolumn{2}{|c|}{$\begin{array}{c}\text { Evolución últimos } 10 \\
\text { años }\left(E_{i}\right)\end{array}$} \\
\hline & Media & Des. tip. & Media & Des. tip. \\
\hline 1. Base territorial para el desarrollo de actividades agrarias y forestales & 4,66 & 1,793 & 4,79 & 2,033 \\
\hline 2. Base territorial para el desarrollo de la industria agroalimentaria & 4,36 & 2,014 & 4,71 & 2,196 \\
\hline 3. Base territorial para el desarrollo de otro tipo de industrias & 4,07 & 2,338 & 4,32 & 2,540 \\
\hline 4. Base territorial para el desarrollo de empresas de servicios & 5,36 & 1,924 & 5,99 & 2,163 \\
\hline 5. Base territorial para el disfrute y mantenim. del paisaje, flora y fauna & 4,93 & 1,861 & 5,24 & 1,952 \\
\hline 6. Base territorial de una red de espacios naturales protegidos & 4,34 & 2,122 & 4,71 & 2,236 \\
\hline 7. Contribución a la calidad ambiental del conjunto de la región & 4,62 & 2,037 & 4,91 & 2,289 \\
\hline 8. Asentamiento de las sociedades rurales (pueblos) & 5,22 & 1,902 & 5,42 & 2,116 \\
\hline 9. Zona de residencial para individuos urbanos & 5,21 & 2,309 & 5,68 & 2,549 \\
\hline 10. Mantenimiento del legado patrimonial histórico-artístico y el folclore & 5,34 & 2,053 & 5,74 & 2,178 \\
\hline 11. Marco para actividades de ocio (turismo rural, etc.) & 5,26 & 2,067 & 5,79 & 2,183 \\
\hline Utilidad (UP) & \multicolumn{2}{|c|}{ Media (Des .típ.) } & \multicolumn{2}{|c|}{$4,91(1,625)$} \\
\hline Variación de la utilidad $(\triangle U P)$ & \multicolumn{2}{|c|}{ Media (Des. tip.) } & \multicolumn{2}{|c|}{$5,26(1,656)$} \\
\hline
\end{tabular}

Las ponderaciones $\left(w_{i}\right)$ calculadas en el anterior apartado pueden ser de utilidad para cuantificar el bienestar (o utilidad) social derivado de la funcionalidad del medio rural. Tal y como demuestra Zahedi (1987), los pesos derivados de la aplicación de la técnica AHP permiten obtener una función de utilidad multiatributo del centro decisor considerado (cada encuestado en nuestro caso). Estas funciones multiatributo pueden ser bien aditivas (Kamenetzky, 1982) o multiplicativas (Barzilai y Golani, 1994). Así, considerando la primera de las formulaciones mencionadas, la utilidad derivada del desempeño del medio rural para un individuo $k$ puede expresarse como sigue:

$$
U_{k h}=\sum_{i=1}^{i=11} w_{i k} \cdot U_{i k h}
$$

donde $U_{k h}$ es la utilidad total proporcionada al individuo $k$ por el desempeño funcional del medio rural en una determinada situación o alternativa $h, w_{i k}$ son los pesos de las diferentes funciones $i$ para el individuo $k$, y $U_{i k h}$ representan la utilidad parcial proporcionada por el desempeño particular de la función específica $i$ en la alternativa $h$ al individuo $k$. 
La agregación de diferentes estructuras de preferencias individuales al objeto de obtener una función de utilidad social ha sido un problema largamente tratado en la literatura económica (Arrow, 1951; Sen, 1970), llegando a la conclusión de que la única forma para alcanzar dicho objetivo es utilizando información sobre la intensidad de las preferencias individuales, lo cual exige comparaciones interpersonales de la utilidad. Más recientemente Keeney (1976) ha demostrado que si se considera una estructura de preferencias individuales expresadas a través de funciones de utilidad cardinales, tal y como la formulada por la expresión [4], sí existe una función cardinal de utilidad agregada (social) que soporte las condiciones básicas para efectuar agregaciones. Tras la demostración de Keeney (1976), diferentes autores han desarrollado procedimientos de agregación de preferencias individuales a través de una función de utilidad multiatributo agregada (Bodily, 1979). Sin embargo, todos ellos presentan como dificultades la necesidad de un alto grado de interacción con los individuos del grupo analizado y su complejidad operativa (Goicoechea et al., 1982). Tal circunstancia ha motivado que tales procedimientos apenas hayan sido implementados en aplicaciones empíricas reales, haciendo igualmente complicado su aplicación a este caso de estudio. A pesar de las circunstancias comentadas, en esta investigación ha parecido oportuno considerar como un proxy razonable de la utilidad social $\left(\tilde{U}_{h}\right)$ la media aritmética de las utilidades individuales $U_{k h}$ :

$$
\widetilde{U}_{h}=\frac{\sum_{k=1}^{k=m} U_{k h}}{m}
$$

A pesar de las limitaciones que tal opción conlleva, su cálculo puede resultar útil de cara a obtener unos primeros indicios de la utilidad percibida por el conjunto de la sociedad analizada y los grupos que la conforman en relación al desempeño multifuncional del medio rural. De este modo, las variables $C_{i}$ pueden considerarse como una valoración normalizada de la utilidad percibida por los individuos en relación a cada una de las funciones ejercidas por el medio rural castellano y leonés en el momento presente. Así, adaptando la expresión [5], cabe expresar como sigue la utilidad percibida $(U P)$ por el individuo $k$ por tal desempeño actual:

$$
U P_{k}=\sum_{i=1}^{i=11} w_{i k} \cdot C_{i k}
$$

Los resultados descriptivos de esta nueva variable también se presentan en la Tabla 4 (véase última fila). Así, considerando como antes se comentó la media como un proxy adecuado de la utilidad social, puede comentarse que la utilidad percibida por el conjunto de la sociedad regional acerca del desempeño actual de la multifuncionalidad rural es moderadamente insatisfactoria, con una valoración agregada de 4,91 sobre 10, puntuación significativamente inferior a 5 .

Al igual que se hizo anteriormente en relación a las preferencias $\left(w_{i}\right)$, en este caso también se ha analizado la heterogeneidad de las percepciones de los individuos sobre el desempeño actual de los distintos roles asignados al medio rural regional. Para ello se han utilizado igualmente modelos de regresión múltiple 'paso a paso hacia atrás' para cada $C_{i}$ y para la nueva variable $U P$. Los resultados obtenidos son los que aparecen reflejados en la Tabla 5. 


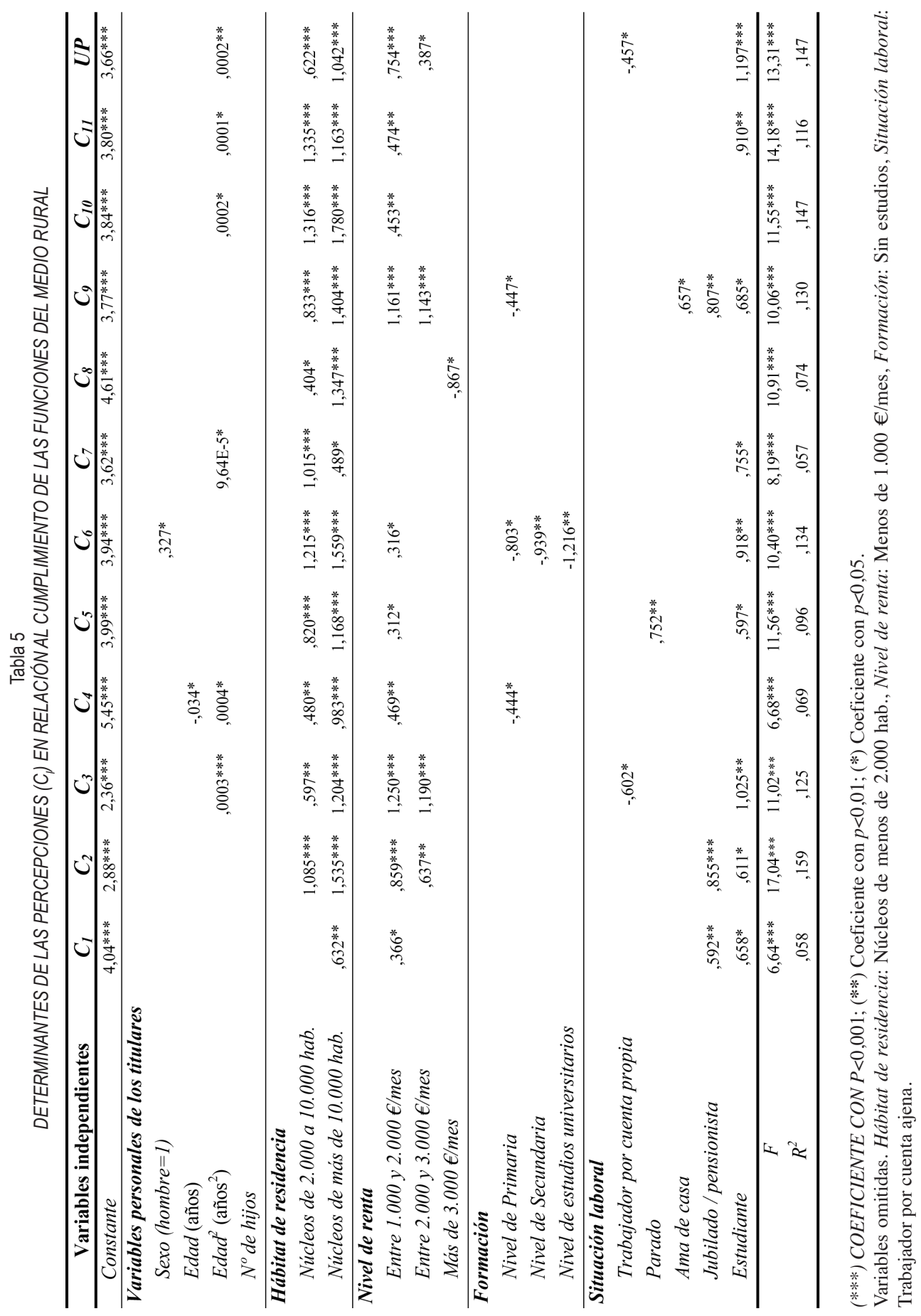


De los resultados de las regresiones realizadas, la circunstancia más destacable es la significación de las variables edad, hábitat y renta. En este sentido resulta llamativo cómo a medida que aumenta el tamaño del municipio de residencia, los individuos mejoran la percepción sobre el cumplimiento de todas las funciones realizadas por el medio rural castellano y leonés. Así, los ciudadanos urbanos, que tienen un conocimiento más indirecto del medio rural regional, son los que perciben una imagen más positiva del desempeño actual del conjunto de funciones propias de estos territorios. De igual forma cabe comentar que, de manera generalizada, son las clases medias (rentas entre 1.000 y 3.000 euros al mes) las que tiene un mejor concepto de la situación del medio rural hoy en día, presentando una valoración más elevada para la mayoría de funciones planteadas.

Lógicamente, los resultados antes comentados se reflejan igualmente en los coeficientes significativos obtenidos en la regresión realizada para la utilidad percibida $(U P)$. De estos resultados se puede deducir que los colectivos sociales más insatisfechos acerca del actual desempeño multifuncional del medio rural son los residentes en núcleos menores de 2.000 habitantes y con rentas inferiores a 1.000 euros al mes, en especial los jóvenes (entre 16 y 30 años) que ya se han incorporado al mercado laboral (no estudiantes). Se trataría, en este caso, del grupo de individuos rurales jóvenes, que han terminado sus estudios, pero encuentran dificultades para encontrar un empleo suficientemente remunerado en su lugar de residencia. Por ello, es el colectivo que se muestra más crítico con la situación actual del mundo rural, dada la imposibilidad de que éste pueda representar una alternativa de futuro en términos de empleo y bienestar.

\section{Percepciones sociales sobre la evolución de la multifuncionalidad rural}

La Tabla 4 ofrece igualmente información sobre los resultados de la opinión de la sociedad castellana y leonesa en relación a cómo ha evolucionado el desempeño de cada una de las funciones realizadas por el medio rural regional en los últimos 10 años (variables $E_{i}$ ), para lo que se ha utilizado una escala de 0 (ahora se cumple muchísimo peor) a 10 (ahora se cumple muchísimo mejor). A este respecto también se aprecian unas puntuaciones relativamente bajas y homogéneas, cuyas medias están comprendidas en un rango inferior a 2 puntos en una escala de 10, oscilando entre 4,32 y 5,99. En cualquier caso, cabe destacar una serie de funciones que el conjunto de la sociedad considera han evolucionado positivamente (puntuación media significativamente por encima de 5). Se trata de la funcionalidad económica como base para el desarrollo de empresas de servicios $(5,99)$, las funciones recreativas y culturales (marco para actividades de ocio y el mantenimiento del legado patrimonial, con promedio del 5,79 y 5,74, respectivamente), las funciones residenciales (zona residencial para individuos urbanos y asentamiento de las sociedades rurales, con medias de 5,68 y 5,42, respectivamente) y la funcionalidad medioambiental con base para el disfrute del paisaje, flora y fauna $(5,24)$. En el lado opuesto, con puntuaciones promedio significativamente inferiores a 5, se encuentran las funciones económicas como base territorial para el desarrollo de industrias no agroalimentarias, de industrias agroalimentarias y actividades agrarias (con medias de 4,32, 4,71 y 4,79, respectivamente) y las funciones medioambientales como base territorial de una red de espacios naturales protegidos y la contribución a la calidad ambiental del conjunto de la región (puntuaciones promedio de 4,71 y 4,91, respectivamente). 
Relacionando la percepción de la evolución del desempeño de las diferentes funciones del medio rural durante la pasada década con la percepción de la situación actual, se aprecia una fuerte correlación entre ambas variables $\left(C_{i}\right.$ y $\left.E_{i}\right)$, con coeficientes de correlación de Pearson significativos y superiores a 0,75 para todo $i$. Así pues, se evidencia cierta lógica en la percepción social de esta cuestión, en la medida que el conjunto de la sociedad regional considera que los roles del medio rural cuyo desempeño ha empeorado durante los últimos años (las funciones económicas y las medioambientales), son los que actualmente peor se están cumpliendo. Nuevamente parecen detectarse algunas incongruencias entre las percepciones sociales y la evolución objetiva del medio rural regional. Así, por ejemplo no cabe encontrar una explicación al hecho de que se considere negativa la evolución experimentada por la incorporación del espacio regional a alguna figura de protección ambiental, cuando en la realidad los esfuerzos en ese sentido han sido muy importantes y los espacios protegidos de esta comunidad cubren un porcentaje del territorio similar al de la media nacional. No obstante, parece que la población sí que es consciente del ingente desarrollo que han experimentado las actividades de turismo rural en los últimos años y de la consiguiente valorización positiva de la funcionalidad recreativa y cultural.

Siguiendo el mismo razonamiento anteriormente expuesto, las variables $E_{i}$ pueden considerarse como puntuaciones normalizadas de la variación de utilidad percibida por los individuos en relación a cada una de las funciones a lo largo de los últimos 10 años. Así pues, la expresión [5] puede también adaptarse al objeto de expresar la variación de la utilidad percibida $(\triangle U P)$ por cada individuo $k$, tal y como evidencia la siguiente expresión:

$$
\Delta U P_{k}=\sum_{i=1}^{i=11} w_{i k} \cdot E_{i k}
$$

La última fila de la Tabla 4 refleja asimismo los resultados descriptivos de esta nueva variable. Como proxy de la variación de la utilidad social puede emplearse igualmente su valor promedio, que alcanza una puntuación de 5,26 en una escala de 10. Dicha valoración implica una ligera mejora en la utilidad percibida por el conjunto de la sociedad regional a lo largo de esta última década (valoración significativamente superior a 5). Así, si bien la situación actual no es por lo general satisfactoria, sí existe una percepción de que ésta va mejorando poco a poco.

En la Tabla 6 se muestran igualmente los resultados de los modelos de regresión realizados para el análisis de heterogeneidad en las percepciones de la población, considerando las variables $E_{i}$ y $\Delta U P$ como dependientes y las variables sociodemográficas como explicativas. Así, tal y como ha sucedido en el caso de las opiniones sobre el desempeño funcional actual del medio rural, las variables que han resultado más significativas en el análisis han sido la edad, el tamaño del hábitat y la renta, además del sexo y la condición de ser o no estudiante. Consecuentemente, y en relación a los resultados obtenidos sobre la evolución de la utilidad percibida $(\Delta U P)$, en la medida que a través de esta variable se condensa el conjunto de percepciones relacionadas con las diferentes funciones, cabe comentar que los colectivos con una visión más optimista (más satisfechos) sobre el progreso en el desempeño de los diferentes roles del medio rural son los hombres, las personas de edad avanzada (más de 60 años) y los residentes en núcleos de población intermedios (de 2.000 a 10.000 hab.) o grandes (más de 10.000 hab.). Por tanto, la bolsa de mayor insatisfacción al respecto la presentan las muje- 


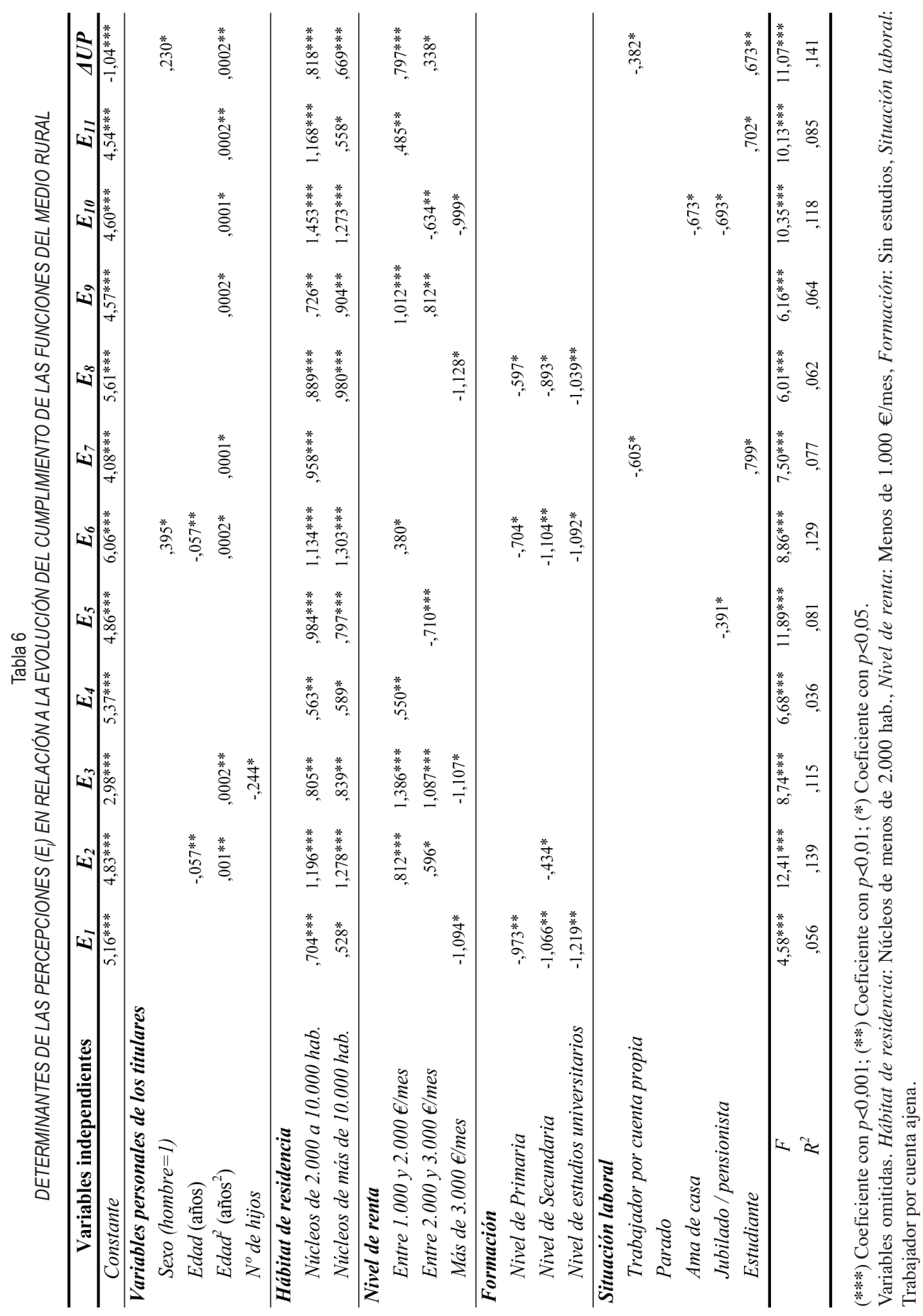


res jóvenes (entre 16 y 30 años), residentes en pueblos de menos de 2.000 habitantes y que ya se han incorporado al mercado de trabajo (no estudiantes). Nuevamente, este resultado está en consonancia con la problemática de los colectivos que más se están viendo afectados por la crisis rural de Castilla y León, como son los jóvenes, especialmente mujeres, que viven en los municipios más pequeños y que cuentan con unas posibilidades muy reducidas para incorporarse al mercado laboral o para disfrutar de una red de servicios sociales y de ocio de calidad (Rico y Gómez, 2009).

\section{CONCLUSIONES}

Uno de los efectos perniciosos derivado del proceso de globalización de los mercados ha sido el acentuado desequilibrio territorial que se ha producido en muchos países, en los que amplias zonas rurales se han llevado la peor parte. El desmantelamiento del tejido económico tradicional rural basado casi en exclusividad en el sector agrario ha motivado la crisis de estos espacios y la necesidad de reorientar su capacidad productiva hacia otro tipo de actividades. A este respecto, surge el concepto de multifuncionalidad rural como posibilidad de reajuste económico de las zonas rurales basado en la diversificación territorial hacia actividades independientes y/o complementarias a las agrarias. Se trata de aprovechar todas aquellas funciones que el medio rural, en su más amplia concepción, puede ofrecer y que, además, presentan una demanda creciente.

Estas demandas ciudadanas en favor de un medio rural multifuncional, especialmente aquellas relacionadas con la provisión de bienes y servicios de carácter público, justificaría la intervención de las administraciones al objeto de minimizar los fallos de mercado existentes (provisión de bienes y servicios que no son remunerados por los mercados). Por ello, y con objeto de determinar la dirección que han de tomar las políticas públicas para maximizar la satisfacción de la sociedad en su conjunto, conviene analizar previamente tanto la oferta de los bienes y servicios procedentes del campo, como la demanda existente hacia ese tipo de productos. La finalidad de este trabajo ha sido el estudio de ese segundo cometido, tomando como caso de aplicación empírica las zonas rurales de Castilla y León. Al respecto, cabe reseñar que los ciudadanos castellanos y leoneses presentan una demanda hacia los bienes y servicios que ofrece el mundo rural claramente multifuncional, ya que muestran sus preferencias tanto hacia las funciones más tradicionales basadas en las producciones agroganaderas o hacia el espacio rural como hábitat de residencia, como hacia otras funciones más novedosas relacionadas con la protección medioambiental o el uso de las zonas rurales con fines lúdicos y culturales.

La cuantificación de estas preferencias difiere ostensiblemente del reparto presupuestario por ejes recogido en el Programa de Desarrollo Rural para Castilla y León en el periodo 2007-2013, donde se priorizan en primer lugar las acciones del Eje 1 de apoyo económico dirigidas a la agricultura y el sector agroalimentario con un $58,4 \%$ de la financiación total (funcionalidad económica con unas preferencias sociales del 36,2\% según la encuesta realizada en este trabajo), seguido de las medidas del Eje 2 relacionadas con la protección medioambiental con el $26,9 \%$ de financiación (funcionalidad medioambiental ponderada un $22,4 \%$ según la sociedad) y finalmente los Ejes 3 y 4 referidos a las acciones destinadas a mejorar la calidad de vida y diversificar la economía de las zonas rurales bajo un enfoque 
de gestión ascendente o enfoque LEADER con el 14,7\% de financiación (funcionalidades residencial y recreativa con una ponderación social total del 41,3\%). En consecuencia, puede afirmarse que la actual política de desarrollo rural en Castilla y León no está respondiendo a las demandas del conjunto de la sociedad regional, sobre todo en lo referente al apoyo de las funciones de corte más social, que tienen que ver con la pervivencia de las sociedades rurales y de su legado patrimonial para el disfrute (residencia y ocio) del conjunto de la ciudadanía. En cualquier caso, es necesario hacer la salvedad de que el conjunto de funciones inherentes a los espacios rurales están estrechamente relacionadas entre sí, y que su cumplimiento individualizado incide sobre el cumplimiento de las restantes, con lo que el mayor apoyo público de alguna de ellas también incidirá positivamente sobre las demás.

Por otro lado, la población en general percibe que actualmente el mundo rural no está desempeñando las funciones que tiene asignadas de manera satisfactoria, opinión que cabe atribuir a la actual situación de decadencia demográfica y económica de muchos pequeños municipios. No obstante, y a tenor de las respuestas de la ciudadanía, se considera que en los últimos años esta situación está mejorando levemente, sobre todo en lo que respecta a las funciones culturales y recreativas. A este respecto, se considera significativo señalar que se ha detectado una cierta desinformación de los individuos sobre la actual situación general del mundo rural, ya que sus percepciones acerca de algún aspecto en concreto distan bastante de la realidad objetiva del medio rural de la región objeto de estudio.

Las opiniones acerca de la multifuncionalidad rural vertidas por el conjunto de los ciudadanos de Castilla y León difieren dependiendo de la situación particular de cada individuo. Así, en términos generales, el colectivo que se encuentra más insatisfecho con el actual devenir de los espacios rurales es precisamente aquel que más se encuentra afectado por la crisis rural, esto es, el conjunto de personas jóvenes que viven en los municipios más pequeños, especialmente mujeres, que desean incorporarse al mercado de trabajo rural porque han finalizado sus estudios, pero que encuentran serias dificultades para hacerlo.

Para terminar cabe comentar que todos estos resultados constituyen un elemento informativo útil para los decisores políticos a la hora de diseñar e implementar la política rural. Efectivamente, si se persigue que ésta sea una política pública realmente al servicio de la ciudadanía, los resultados alcanzados pueden ser de interés para la selección de los instrumentos políticos más adecuados al objeto de mejorar el desempeño de la funcionalidad rural, maximizando con ello el bienestar percibido por el conjunto de la sociedad.

\section{BIBLIOGRAFÍA}

AGUARÓN, J. y MORENO-JIMÉNEZ, J.M. (2000): «Stability intervals in the analytic hierarchy process». European Journal of Operational Research, $\mathrm{n}^{\circ} 125(1), 114-133$.

ARROW, K.J. (1951): Social Choice and Individual Values. New York. John Wiley \& Sons.

BARAJA, E. (2003): «La despoblación, un fenómeno demográfico todavía vigente en Castilla y León» en La lucha contra la despoblación todavía necesaria: políticas y estrategias sobre la despoblación en las áreas rurales del siglo XXI (García Pascual, ed.). Jaca (Huesca). CEDDAR, Centro de Estudios sobre la Despoblación y el Desarrollo de Áreas Rurales. 
BARZILAI, J. (1997): «Deriving weights from pairwise comparison matrices». Journal of the Operational Research Society, $\mathrm{n}^{\circ}$ 48(6), 1226-1232.

BODILY, S.E. (1979): «A delegation process for combining individual utility functions». Management Science, $\mathrm{n}^{\circ}$ 25, 1035-1041.

BROUWER, F. (ed.) (2004): Sustaining agriculture and the rural environment, governance, policy and multifunctionality. Massachussets. Edward Elgar publishing.

CAG, CONSEJERÍA DE AGRICULTURA Y GANADERÍA - JUNTA DE CASTILLA Y LEÓN (2009): Programa de Desarrollo Rural de Castilla y León 2007-2013 (actualización febrero 2009). Valladolid. CAG.

CLOUT, H. (1991): Rural change in Europe: Research programme on farm structures and pluriactivity. Oxford. Arkleton.

DUKE, J.M. y AULL-HYDE, R. (2002): «Identifying public preferences for land preservation using the analytic hierarchy process». Ecological Economics, $\mathrm{n}^{\circ}$ 42(1), 131-145.

EASLEY, R., VALACICH, J. y VENKATARAMANAN, M. (2000): «Capturing group preferences in a multicriteria decisión». European Journal of Operational Research, $\mathrm{n}^{\circ}$ 125(1), 73-83.

FORMAN, E. y PENIWATI, K. (1998): «Aggregating individual judgments and priorities with the Analytic Hierarchy Process». European Journal of Operational Research, $\mathrm{n}^{\mathrm{o}}$ 108(2), 165-169.

GARCÍA PASCUAL, F. (Coord.) (2003): La lucha contra la despoblación todavía necesaria: políticas y estrategias sobre la despoblación en las áreas rurales del siglo XXI. Jaca (Huesca). CEDDAR, Centro de Estudios sobre la Despoblación y el Desarrollo de Áreas Rurales.

GARCÍA SANZ, B. (2003): «La industria agroalimentaria y el desarrollo rural». Papeles de Economía Española, n ${ }^{\circ}$ 96, 96-111.

GARCÍA SANZ, B. e IZCARA, S. (2000): «Pluriactividad y diversificación de ingresos en el medio rural». Sociología del trabajo, nueva época, $\mathrm{n}^{\circ}$ 38, 119-134.

GOICIECHEA, A.; HANSEN, D.R. y DUCKSTEIN, L. (1982): Multiobjective decision analysis with engineering and business applications. New York. John Wiley \& Sons.

GÓMEZ MENDOZA, J. (2001): «Las nuevas funciones socioeconómicas y ambientales de los espacios rurales» en El mundo rural en la era de la globalización (García Pascual, P., coord.). Madrid. Ministerio de Agricultura, Pesca y Alimentación, 111-148.

GÓMEZ-LIMÓN, J.A. y BARREIRO, J. (coords.) (2007): La multifuncionalidad de la agricultura en España. Madrid. Ministerio de Agricultura, Pesca y Alimentación.

GÓMEZ-LIMÓN, J.A.; ATANCE, I. y RICO, M. (2007): «Percepción pública del problema de la despoblación del medio rural en Castilla y León». AGER. Revista de Estudios sobre Despoblación y Desarrollo, $\mathrm{n}^{\circ}$ 6, 9-60.

GONZÁLEZ REGIDOR, J. y TROITIÑO, M.A. (2008): «El nuevo desafío rural» en Desarrollo rural sostenible: un nuevo desafío (González Regidor, J., coord.). Madrid. Ministerio de Medio Ambiente y Medio Rural y Marino, 19-42.

GOURLAY, D. y SLEE, B. (1998): «Public preferences for landscape features: a case study of two Scottish environmentally sensitive areas». Journal of Rural Studies, n $14(2), 249$ 263. 
HOGGART, K.; BULLER, H. y BLACK, R. (1995): Rural Europe. Identity and change. London. Edward Arnold.

IESA, INSTITUTO DE ESTUDIOS SOCIALES DE ANDALUCÍA (2008): Agrobarómetro 2008. Córdoba. IESA.

KALLAS, Z.; GÓMEZ-LIMÓN, J.A. y BARREIRO, J. (2007): «Decomposing the Value of Agricultural Multifunctionality: Combining Contingent Valuation and the Analytical Hierarchy Process». Journal of Agricultural Economics, $\mathrm{n}^{\circ}$ 58(2), 218-241.

KAMENETZKY, R. (1982): «The relationship between the analytic hierarchy process and the additive value function». Decision Science, $\mathrm{n}^{\circ}$ 13(4), 702-713.

KEENEY, R.L. (1976): «A group reference axiomatization with cardinal utility». Management Science, $\mathrm{n}^{\circ}$ 23(1), 140-145.

LÓPEZ TRIGAL, L. (coord.) (2003): La ordenación del territorio en Castilla y León. Valladolid. Consejo Económico y Social de Castilla y León.

MARSDEN, T.K. (2006): «The road towards sustainable rural development: issues of theory, policy and practice in a European context» en Handbook of rural studies (Cloke, P.J.; Marsden, T.K. y Mooney, P.H., eds.). London. Sage Publications, 201-212.

MARSDEN, T.K.; MURDOCH, J.; LOWE, P.; MUNTON, R. y FLYNN, A. (1993): Constructing the Countryside. London. University College, London Press.

MAYA, A. (2006): «Las políticas de desarrollo y el futuro del mundo rural en Castilla y León» en Estrategias territoriales de desarrollo rural (Frutos, L.M. y Ruiz E., eds.). Zaragoza. Institución Fernando el Católico, Diputación Provincial de Zaragoza., 105124.

MAYA, A. (2008): El desarrollo rural como estrategia territorial: las perspectivas de los espacios rurales en Castilla y León. León. Secretariado de publicaciones de la Universidad de León.

MAYA, A. e HIDALGO, C. (2009): «Nuevas funciones y desarrollos de los territorios rurales europeos: su necesaria adaptación a métodos de producción duraderos y sostenibles». Boletín de la Asociación de Geógrafos Españoles, $\mathrm{n}^{\circ}$ 49, 255-279

MIRANDA, B. y RICO, M. (2007): «La agricultura de Castilla y León: situación actual y retos de futuro» en El futuro de la agricultura en Castilla y León (Gómez-Limón, J.A., coord.). Palencia. Itagra.ct., 29-49.

MOLINA, M. (2003): «Reflexiones sobre el desarrollo rural en Castilla y León: problemática y estrategias futuras» en Libro Blanco de la Agricultura y el Desarrollo Rural (Ministerio de Agricultura, Pesca y Alimentación). Madrid. Ministerio de Agricultura, Pesca y Alimentación, 1-32.

MOLINERO, F. y BARAJA, E. (2011): «Urbanización del espacio rural en Castilla y León. Transformaciones, situación y perspectivas» en Geografía y desafíos territoriales en el siglo XXI (Gozálvez, V. y Marco, J.A., coords.). Alicante. Asociación de Geógrafos Españoles, 449-462.

MOLINERO, F.; MAYORAL, R.; GARCÍA BARTOLOMÉ, J.M. y GARCÍA FERNÁNDEZ, G. (coords.) (2004): Atlas de la España Rural. Madrid. Ministerio de Agricultura, Pesca y Alimentación.

MOYANO, E. y GARRIDO, F.E. (2007): «A propósito de la multifuncionalidad. Discursos y políticas sobre agricultura y desarrollo rural» en La multifuncionalidad de la agricultura 
en España (Gómez-Limón, J.A. y Barreiro, J., coords.). Madrid. Ministerio de Agricultura, Pesca y Alimentación, 59-75.

OECD (2001): Multifunctionality Towards an analytical framework. Paris. OECD publications.

OECD (2003): Multifunctionality The policy implications. Paris. OECD publications.

OECD (2006): The new rural paradigm: policies and governance. Paris. OECD publications.

PÉREZ, A. y CABALLERO, J.M. (2004): La nueva ruralidad en Europa y su interés para América Latina. Washington DC. Banco Mundial y FAO.

QUINTANA, J.; CAZORLA, A. y MERINO, J. (1999): Desarrollo rural en la Unión Europea: modelos de participación social. Madrid. Ministerio de Agricultura, Pesca y Alimentación.

RICO, M. y GÓMEZ, J.M. (2009): «La contribución de la mujer en la economía rural de Castilla y León». Revista de Economía Agraria y Recursos Naturales, nº 18, 51-77.

RICO, M. y GÓMEZ-LIMÓN, J.A. (2008): «Sociedad y desarrollo rural en Castilla y León: un estudio de opinión pública». Boletín de la Asociación de Geógrafos Españoles, n 48 , 199-223.

SAATY, T. (1980): The Analytic Hierarchy Process. New York. McGraw.

SEN, A. (1970): «The impossibility of a Paretian liberal». Journal of Political Economics, $\mathrm{n}^{\mathrm{o}} 78(1), 152-157$.

VAN HUYLENBROECK, G. y DURAND, G. (2003): Multifunctional Agriculture: a new paradigm for European agriculture and rural development. Farnham (Reino Unido). Ashgate publishing.

VARIYAM, J.N.; JORDAN, J.L. y EPPERSON, J.E. (1990): «Preferences of citizens for agricultural policies: evidence from a national survey». American Journal of Agricultural Economics, $\mathrm{n}^{\circ}$ 72(2), 257-267.

ZAHEDI, F. (1987): «A utility approach to the Analytic Hierarchy Process». Mathematical Modelling, $\mathrm{n}^{\circ}$ 9(2), 387-395. 